\title{
A Boa Fé Objetiva, uma noção presente no conceito alemão, brasileiro e japonês de contrato ${ }^{1}$
}

\author{
Véra Maria Jacob de Fradera \\ Professora na Universtdade Fidiral do Rio Grande do Sul \\ ADVOGada EM PORTo Alegre \\ Mestre e DOUTORA Em Direito plia Universidade de Paris II
}

\section{Introdução}

A escolla do tema deve-se ao aumento crescente do relacionamento entre Brasil e Japão, seja no plano comercial, seja no cultural, cuja mais recente demonstração é a assinatura, em 2002, de Convênio entre a Lam Schoolda Universidade de Toboku, Sendai e a Faculdade de Direito da UFRGS. Dentre os inúmeros assuntos passíveis de ser objeto de reflexão comparatista, optamos pelo contrato, pois ele constitui a base de todas as relações jurídicas civis e comerciais, é a mola propulsora das trocas, e, ao lado da familia e da propriedade, um dos pilares fundamentais da ordem jurídica privada,

Dentro do tema «contrato», escolhemos realizar a comparação no que respeita a concepção e aplicação do princípio da boa fé objetiva ${ }^{2}$ em três sistemas, a saber, o alemão, o brasileiro e o japonês, buscando demonstrar a semelhança entre o $B G B$ e o Minpố, fundada precipuamente no fato de os alemães e os japoneses serem povos dedicados ao comércio, sem nenhum resquício de canonismo em suas origens, diversamente do modelo brasileiro, eivado destas influências, ao lado de outras, como o Direito visigótico, resultando, dessa mescla, algumas das peculiaridades do Código Civil brasileiro. No referente à concepção da

1 - Eiste estudo tem origem em palestra proferida na Facuidade de Direito da UFRGS, por ocasião do evento rehuivo ao acordo de Cooperaçầo entre a Liniversidade Tohoku / Sendá e a Fiac. Dir. da UFRGS, em setembro de 2002. V. a respeito, edição especial da Revista da Faculdade de Direito da UFRGS, setembro 2002.

${ }^{2}$ - A única nota com traços de originalidade neste estudo é a de comparar três sistemas tão distintos em um sem número da aspectos, e, não obstante, aproximados peła noção de contrato, pois estamos perfeitamente conscientes do fato de, como afirmado pelo professor Guido ALPA, la tetteratura sulla clausula generale di buona ferte è sterminata, sia nell'esperienza italiana, sia nelle esperienze degh altri ordinanenti continentoli, in "Il Diritto Giurisprudenziale in Itália e nel Mondo", Atas do Congresso realizado em Cagliari / Chia, 15-17 giugno 1995, p. 31. 
Boa Fé objetiva, sua adoção, ainda de forma não expressa ${ }^{3}$, deve-se a forte inspiração romana, presente no projeto de Código Civil brasileiro, de autoria do insigne jurista Teixeira de Freitas. Seu sucessor, Clóvis Bevilacqua, neste particular, manteve-o inalterado. A tradição positivista fez com que, durante muitos anos, o direito civil brasileiro ignorasse os recursos decorrentes da aplicação da Boa Fé em sentido objetivo, restringindo-se, por décadas, aos limites da Boa Fé em sentido subjetivo, prevista pelo legislador, de maneira expressa.

Antes de iniciar propriamente nossa análise comparatista, faremos brevíssima referência à maneira interessante como o Japão adotou uma noção tomanista de contrato.

De acordo com David - Spinosi ${ }^{4}$, o Japão esteve praticamente isolado do Ocidente durante aproximadamente 250 anos, mais precisamente, até o ano de 1853 , quando iniciou alguns contactos com seus vizinhos, os chineses, sofrendo, então, influência da China, Contudo, conservou o Japão, em relação ao pensamento chinês, uma marcante originalidade, devido, por um lado, ao próprio caráter dos japoneses, e, por outro, em virtude do isolamento voluntariamente mantido, até a abertura do país, no já mencionado ano de $1853^{5}$. É televante referir ainda o fato de os primeiros documentos jurídicos japoneses remontarem ao ano de $646^{6}$, destacando-se, neste período, a elaboração de regras repressivas - ritsu-e de regras administrativas, as $r y \hat{o}^{7}$.

A primitiva sociedade nipônica era dividida em classes, primando pela ausência da idéia de direito. Nestas remotas épocas, há uma espécie de repúdio à regulamentação da sociedade mediante regras jurídicas, consideradas pouco flexíveis, pois suas soluções, de acordo com tal pensamento, estão desprovidas de nuances.

Desta sorte, desenvolveu-se na sociedade japonesa, um conjunto de regras, originadas da conveniência e da motal, reguladoras, em todas as circunstâncias da vida, da conduta a ser seguida pelos individuos nas suas relações com os demais. Estas regras são denominadas giri, as quais substituem o direito e, segundo alguns juristas nipônicos, a própria moral. Para um japonês, o fato de não respeitar um dos giri, no qual ele está implicado, reptesenta uma vergonha, situação descrita pela expressão "perda da face».

Este código de honra, puramente costumeiro, tornou inútil, até época assaz recente, a intervenção do Direito e de seus mecanismos. .

Em 1868, tem início a denominada era Mejii, marcando os primórdios da ocidentalização do Japão, ocorrendo um processo de tenovação da sociedade japonesa,

${ }^{3}$ - A explicação para o fato de Teixeira de Freitas não tex inclúdo um artigo expresso sobre a Boa Fé Objetiva em seu projeto, poderia estar na sua idéia de unir as obrigaçōes civis e comerciais. Como a Boa Fé Objetiva já estava prevista no Código Comercial de 1850 , desempenhando a funçäo interpretaciva, não haveria necessidade de prevê-la expressamente para as obrigaçōes civis.

4. In Les grands systimes de droit contemporains, Dalloz, 2002, 11 a.ed.p. 426 e segs.

5. Apesar dessa opção pelo isolamento, houve alguns contactos importantes com o Ocidente: no século XVII, os holandeses negociavam com os japoneses e, no século XVIII, os portugueses estavam nuito presentes na terra do sol nascente. Jesuitas de váxias nacionalidades lá pregayam o cristianismo.

6 - Foram produzidos na era Taika, cujo inicio é fixado em 646.

" - Segundo referem R. DAVID. C. SPINOSI, neste periodo, os japoneses se encaminham para uma concepção jurídica revestida de uma certa importância, criam escolas onde o direito é ensinado e os ritsu-ryô são comentados. Os mestres franceses salientam, contudo, que, nas compilações jurídicas então produzidas, a idéia de direito subjecivo ainda é algo temoto, in Les grands Systèmtes de Droit Contemporains, supra cit., p. 426. 
surgindo um Estado democrático no lugar do Estado Feudal até então existente.

Um desenvolvimento extraordinário coloca o Japão entre as primeiras nações de nossa época no referente ao comércio mundial. Uma legislação moderna é então elaborada, visando aproximar o direito japonês dos sistemas jurídicos ocidentais.

Qual a razão de tantas modificações?

$O$ fundamento de tantas e vatiadas transformações pode ser encontrado no florescimento da era Meiji⿱ , quando o Japão decidiu, em 1858, pôr fim aos Tratados desiguais, firmados com os Estados Unidos, Reino Unido, França e Países Baixos. ${ }^{9}$

Foi então encetada a adoção de Códigos, inspirados dos modelos europeus, movimento cujo início foi marcado pela tradução do Code Civil francês, iniciada no ano de 1869 e concluída cinco anos mais tarde.

A escolha do Code Civil como primeiro modelo ocidental a ser conhecido pelos juristas japoneses teve vários motivos determinantes, como bem observa o professor Jacques Robert ${ }^{\text {t0 }}$, um dos mais importantes conhecedores do direito japonês no Ocidente.

Em primeiro lugar, a França era, na época, o único país a possuir Códigos completos, cuja excelência já havia sido comprovada.

Em segundo lugar, o Esprit des Lois de Montesquieu foi a primeira obra jurídica francesa a ser traduzida e publicada no Japão, tendo servido de base para as primeiras reflexões constitucionais japonesas, à maneira ocidental, nos inícios da era Meiji. De acordo com a lição do professor Robert, os primeiros textos constitucionais do Japão moderno apresentam a marca do liberalismo das Lumières", textos onde são invocados o princípio representativo, o princípio democrático e o da internacionalização jurídica, valorizando-se o direito comparado. Inseriu-se nos textos uma declaração ${ }^{\mathrm{t} 2}$, semelhante à Declaração dos direitos do homem, onde foram revogados os antigos costumes discriminatórios, buscandose seguir os princípios racionais universalmente reconhecidos. Da mesma forma, eram proclamados os princípios da separação dos poderes e da igualdade de todos perante a lei ${ }^{13}$.

Contudo, apesar de tantos esforços, o Japão ainda não lograra ocidentalizar-se o suficiente. Desta sorre, o governo japonês decidiu recorrer à colaboração de rrês juristas franceses, George Appert, Georges Bousquet e Gustave Boissonade de Fontarabie. Foi este último que acabou sendo o autor de vários Códigos para o Japão, dentre os quais, um Código Penal e um Código de Instrução Criminal, em 1877. Quanto ao Código Civil, ele

8. Já nos primeiros anos da era Meiji a presença francesa fez-se sentit, sobretudo no âmbito do direito.

9 - Por esses tratados desiguais, eram attibuídos privilégios exorbitantes (regime de extraterritorialidade, estabelecimento de jurisdições consulares para julgat os conflitos ocorrentes entre japoneses e estrangeiros). Como o direito comum japonês não oferecia garantias suficientes ao seus súditos, teve inicio um movimento nacional no sentido de conferir aos nacionais as mesmas condições. Outro aspecto deveras importante para a ocidentalização do Japão, foi a necessidade de adotat o capitalismo pata manter sua independência frente às potências ocidentais. Por outro lado, uma reforma jurídica se fazia necessária para pôr fim aos Tratados desiguais.

10. $\mathrm{Na}$ introduçào aos txabalhos sobre "Boissonade et la réception du droit français au Japon", colloque organisé par l'Université Panthéon-Assas (Paxis II) et la Maison du Japon à la Cité internationale universitaire de Paris, le 22 novembre 1990, Reme Internationale de Droit Compare, ${ }^{\circ}$ 2, avtil/juin 1991, p. 327 a 331.

11. Ob.cit. p. 328.

12 - Exa o "Juramento imperial dos cinco artigos ", equivalente as nossas Declarações de Direitos.

13 - Idem p. 328. 
teve menor êxito, apesar de o seu autor ter consagtado muitos anos de vida a sua redação.

Somente a grande deteminação dos japoneses foi capaz de terminar esta obta gigantesca.

Esta tradução teve ainda a colaboração de juristas alemães e, em menor númeto, de ingleses, como relata o professor Noda (1962), escrevendo sobre o grande, e até hoje reverenciado, professor Boissonade ${ }^{14}$.

O projeto Boissonade de Código Civil foi tevisto e adotado em 1891, tendo sido conservado o Direito japonês relativamente ao direito de família e sucessões, devido as suas peculiaridades locais. Contudo, sua vigência foi diferida, devido a uma séria oposição, de diversas origens. ${ }^{15}$

Um novo texto foi então preparado, o qual deveria manter grande parte do primeito, mas tal não ocorreu, devido à influência dos projetos de Código alemães, cuja qualidade impressionara os redatores nipônicos. Desta sorte, o Código Civil japonês, adotado em $1896^{16}$, apresenta nírida influência alemã, pois é contemporâneo ao $B G B$, mas isso não significa que não haja contribuições de outros sistemas ${ }^{17}$.

É interessante observar que, neste aspecto, ocorreu no Direito japonês fenômeno semelhante ao vivenciado pelas sociedades latino-americanas, onde a maioria dos Códigos civis é igualmente resultado de uma mescla de vários modelos eutopeus ${ }^{18}$.

Após 1945, uma outra corrente ocidental passou a ter uma certa participação na elaboração do direito japonês, qual seja, o direito norte-americano ${ }^{19}$. Finalmente, em 1947, foi publicado o Código Civil japonês, denominado Mimpâ, o qual recepcionou o princípio da Boa fé objetiva.

14 - Sobre a vida e a obra de Boissonade, consultar o número 2 da Revue Internationale de Drait Comparé, avril.juin 1991, onde vátios aspectos de sua obra săo analisados pelos professores G. ANTONETTI, J. CARBONNIER, E. HOSHINO, Y.OKUBO, E.SEIZELET, J-L.SOURIOUX, bem como o já referido Jacques ROBERT.

15 - De acordo com o professor Jacques Robert, alguns fatores contribuíram pata o fracasso do projeto Boissonade, como a tentativa de apresentar urx projeto demasiado europeu, muito distante das tradições nipônicas. Outros criticaram, mas sen razăo, segundo Robert, o fato de o jurista francês ter, de certa forma, ignorado as tradiçōes nacionais japonesas e năo ter levado en conta, com maior profundidade, as especificidades do país, cultural e fisicamente tăo afastado do Ocidente, raquuela época. Outro fator pesou fortemente para o repúdio ao projeto, pois seu Código foi considerado como revolucionário para a época, onde ele afrmava a noçăo de pessoa, em detrimento da de Estado, fazia ressaltar o indivíduo e não o grupo. Além disso, o Code Napolion já sentia o peso dos anos, enquanto outro modelo, o $B G B$, estreava, como algo totalmente inusitado, no cenário juridico universal. Consultax o artigo cit. p. 329.

!' onde nâo há lugar para a $\mathrm{BFO}$.

17 - Sobre este periodo da história do direito privado japonẹs, consultat o interessante trabalho da profa. Yuko NISHITANI, in "Revista da Faculdade de Direito da Universidade Federal do Rio Grande do Sul, Edição especial, setembro 2003 , p. 9 a 18 , especialmente p. 13.

18 - Vide Orlando GOMES, "As raizes históricas e sociológicas do Código Civil brasileiro" in Revista da AJURIS, n" 6 e nosso "A circulação de modelos juridicos europeus na Anérica Latina, um obstáculo à integração ro Cone Sul ? "In Revista Ciências Sociais, da Universidade Gama Filho, RJ, 1996, Rio de Janeiro.

19 - Para uma visão crítica desse periodo, consultar a interessante obra coletiva, organizada por A Von MEHREN, Law in Japan, 1963. 
Este fato foi de grande relevância, tanto é que, povos vizinhos, como a Coréia do Sul e a China Popular ou Taiwan, foram por ele nitidamente influenciados ${ }^{20}$.

Postos estes dados informativos básicos sobre a ocidentalização do Direito japonês, passaremos ao exame e justificativa da presença do ptincípio da boa fé objetiva nos contratos nos três ordenamentos aqui mencionados, adiantando o reconhecerem os três, mas com acepçóes a alcance um pouco distintos.

É oportuno referir, neste passo, nosso propósito de não abordar a questão da classificação da Boa Fé Objetiva como cláusula geral, pois a brevidade desejada para esse estudo seria então sacrificada ${ }^{21}$.

Tampouco teceremos considerações a respeito da refetência à Boa Fé Objetiva nos contratos de consumo disciplinados nas leis alemã e japonesa, e Código brasileiro de proteção ao consumidot ${ }^{22}$, pois nossa pretensão é a de manter-nos nos limites do contrato civil.

Na Ia parte de nosso estudo, nos ocuparemos das tazões da adoção do conceito de Boa Fé nos três ordenamentos e, na II a parte, examinaremos o alcance dos três textos relativos à Boa Fé objetiva nos Códigos Civis, alemão, brasileiro ejaponês.

I Parte : As razões da adoção do conceito de boa fé objetiva como regra contratual no $B G B$, no Código Civil brasileiro de 2002 e no Minpô de 1947.

20. Para informações a respeito da história da civilização japonesa, vide Edwin O. REISCHAUER, Japan, the story of a Nation, Charles E.Tuttle Company, 1976 e John Whitney HALL, Japan, from Prebistory to Madery Times, Charies Tuttle Company, 1978. Sobre o Direito japonês em geral, consultar: René DavidCamille Jauffret-Spinosi, Les grands Systemes de Droit Contemporains, Dalloz, 11édicion, 2002, Y. NODA, Introduction au droit japonais, Dalloz, 1966; J.H. MOI"ГRX, te droit japonais, Que sais-je ?, 1988; I. KITAMURA, "Une esquisse psycanalystique de l'homme juridique as Japon", Revue Internationale de Droit Compare, 1987, $\mathrm{n}^{\circ} 4$, pp. 791 e segs. ; T.TANIGUCHI, La toi at la coutume an Japon, Études juridiques offertes à M. Julliot de la Morandière, 1964, pp. 571 e segs., H.ODA, Japanere Law, 1992, Yuko NISHITANI "Introdução à História do Japão ", in Revista da Faculdade de Direito da Universidade Federal do Rjo Grande do Sul, Edição Especial, setembro de 2002, tradução do alemão, de Maitê Schrnicht, Luciana Quinto, e revisão da Profa. Dra. Cláudia Lima Marques, pp. 9 e segs.

21 - Sobre as cláusulas gerais, existe cxtensa e variada bibloggrata, sobretudo no plano europeu, remontando os primeiros estudos as primeiras décadas de vigencia do $B G B$. Assirn, a título de exemplo, indicamos: J HEDEMAN, Die Flustst in die Generalklauselm, Eine Gefabr fâr Recht und Stat, Tûbingen, 1933 ; J. ESSER, Principio y Norma en la elaboración juriprudencial del dertabo privado, Bosch, 1961, Generalkatasen als Gegenstand der Sozithissenschaften, mit Beiträgen von K. LUEDERSSEN, E. Noelle NEUMANN, T. RAISER, G. TEUBNER und A. ZIELCKE, Baden-Baden, Nomos Verlag, 1978, Stefano RODOTÀ, "Il tempo delle clausole generale $»$ in Riv. Cint del Dirito Privato, vol. 05, 1986, p. 709 e segs. Luciana Cabella PISU e Luca NANNI (a cura di) Clausole e primipit generali nell argomentazione gizurispruterzidale deghti anni novanta, Cedam, 1998. No Brasil, J. MARTiNS COSTA, "As ctáusulas gerais como fatores de

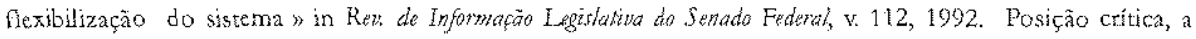
respeito da adoção das cláusulas gerais, devido a sua intervenção demasiado incisiva na autonomia da vontade, in "Desatualização do Projeto de Código Civil na questão da Boa Fé Objetiva nos contratos" , Revista dos Tribunats, fasc. cív., vol. 775, maio 2002, p. 11 a 17, em especial páginas 11 e 12.

22 -Esta opçấo tem ainda outro motivo, o de não consideramos as relaçóes de consumo propriamente contratos, porquanto mais próximas dos denominados "contatos sociais ". Sobre o tema, ver Verena Nygaard BECKER, "A Categoria jutídica dos atos existenciais.Transformação da concepção clássica de negócio juridico", in Revista da Faculdade de Direito de Porto Alegre, ano VII, VII, 1973/1974, p. 15 a 53. 
A)Paradoxalmente, Alemanha, Brasil e Japão sofreram a influência do direito romano, porém, por motivos bastante diversos.

a- A Alemanha, por buscar um sistema jurídico apto a regular a sua mais importante atividade, o comércio e também em razão do prestígio desfrutado por esse Direito em todo o mundo. Aftnidade igualmente na vocação imperialista, expressa na denominação do Chefe de Estado, o Kaiser, vocábulo derivado de Caesar, a autoridade máxima romana.

b- O Brasil, pela via Ordenações, a lei do colonizador português, foi obrigado a adotar um sistema romanista, já bastante mesclado por outros direitos, o árabe e o visigodo. A influência canonista ${ }^{23}$ é igualmente muito importante, marcando o direito brasileiro de forma indelével, sobtetudo no âmbito do direito da família ${ }^{24}$.

c-O Japão, dada a necessidade de ocidentalização, por razões de incremento comercial, optou por inspirat-se no direito alemão, devido as grandes afinidades com a Alemanha, destacando-se, dentre todas, em primeiro lugar, o comércio ${ }^{25}$. Assim, a adoção de uma legislação privada de origem romana deu-se de segunda mão, através dos projetos do $B G B$.

Já a doutrina japonesa reconhece a origem romana da Boa Fé Objetiva, mas sem que isso tenha grande relevância em sua versão contemporânea

Qual a razão de ter o direito romano exercido tamanho fascínio entre os alemães, e indiretamente, entre os japoneses ? ${ }^{26}$.

A tesposta está no faro de o Direito Romano ter vocação à universalidade, suas soluções são claras, idênticas em toda parte, permitindo uma circulação fácil das riquezas. Além disso, o Direito Romano tem como centro o individuo, e o contrato, como legitimação da vontade e poder desse indivíduo, fazendo com que muitos o considerem um dos antepassados mais remotos do liberalismo.

O direito alemão, diversamente de todos os outros povos influenciados pelo sistema romano, continua a atribuir-lhe grande relevância, destacando-se, neste âmbito, a teoria da interpretação e suas técnicas. Desta sorte, o princípio da boa fé está presente, dentre outros aspectos do contrato, na exceção de contrato não cumprido, no $\$ 242$, onde se prescreve dever ser a execução da prestação realizada de acordo com a boa fé . Também na fase pré-

23. - Sobre o assunto, Ernest CAPARROS «Les racines institutionnelles des droits occidentaux dans Le droit ecclesiastique ", in KX.D. KERAMEUS (Ed.) Rapports généraux présentés au XIVe. Congrès Internationat de droit comparé, (Athènes, 1994), 1995, pp. 7-32., Antonio Padoa SCHIOPPA, "Notes on the role of cânon law and on legal historiography ", in Rapports nationaux italiens aux XVYe. Congrès International de Droit Comparé (Athènes, 1994), Milano Giufftè editore, 1994, pp. 15 a 30.

${ }^{24}$ - Vide, Osvaldo Hamilton TAVARES, "A influência do Direito Canônico no Código Civil brasileiro ", Revista de Direito Civil, $\mathrm{n}^{\circ} 34$, p. 46 e segs., Salvatore BERLINGO, "II Diritto «familiare " nellotdinamento canônico ", Riv. Diritto Civ, 1999, pp. 619 e segs.Sobre a atual exigência de flexibilizaçào do Direito Canônico, o excelente artigo de Louts-téon CHRISTIANS, "le droit canonique intemormatif. Conflits de lois et de jurisdictions avec les systèmes étatiques et les autres systèmes religieux en droit matrimonial ", in Ren, crit. drinternat. privé, (2), 1998, pp. 217 e segs.

25. Vale lembrar que, antes das codificações de 1804 e 1900 , a boa fé objetiva era considerada um principio geral de comércio na França e na Alemanha. Consultar sobre esse período, Rudolf MEYER, Bona Fides und lex mercatoria in der europäischen Rechtstradition, Wallstein Verlag, Göttingen, 1994; en língua francesa, nosso comentário, Revue Internationale de Droit Comparé, 1995, vol.1, p. 277.

26. Não referimos o caso do Brasil devido ter sido a adoção de um sistema calcado no Direito Romano, não uma escolha, sim uma imposiçâo do colonizador português, através dás Ordenações do Reino. 
contratual, a boa fé é reclamada, servindo de fundamento à responsabilidade civil, quando da ocorrência da culpa in contrabendo, conceito de origem romana, magistralmente sistematizado por Von Ihering $g^{27}$, antes mesmo da entrada em vigor do $B G B$.

A repercussão desse estudo foi intensa, tendo o conceito de culpa in contrabendo sido recepcionado em vários sistemas, inclusive pela common law americana, mediante a sua divulgação por professores americanos com fotmação alemã, ou por mestres alemães, radicados nos Estados Unidos, exercendo o magistério em Universidades locais ${ }^{28}$.

Uma vez que o direito tomano está na raiz da recepção do conceito de Boa Fé contratual, em todos os ordenamentos onde se faz presente, é importante referir, ainda de forma sucinta, a noção romana de Boa Fé e sua configuração nas modernas Codificações.

\section{B) A noção romana de bona fides}

A sua primeira acepção é de cunho religioso, sendo Fides a deusa da palavra dada, representante da fé jurada e protetora dos segredos. Ela também governava a confiança entre os homens, protegendo os fracos contra os poderosos.

Já a bana fides é um conceito jurídico, cujo conteúdo foi traçado por Cícero: a fides do bonus vir romano era a atitude social do romano que auxilia os demais na medida do possivel e não prejudica a ninguém. A bona fides era a fidelidade à palavra dada e a regra de conduta do homem honesto.

A regra da boa fé nos contratos rem origem nas ações de Boa Fé, ela se faz presente antes mesmo do surgimento da noção de contrato, sendo que os contratos de natureza consensual, tais como os conhecemos hoje ern dia, têm origern nessas ações, as bona fidei judicia ${ }^{29}$.

Este conceito, bastante modificado, vai aparecer nas codificações do século XIX e XX, como veremos a seguir.

27. Em artigo publicado em 1860, intitulado, en sua versão francesa, «De la culpa in contrahendo ou des domages-intérêts dans les conventions nulles ou restées imparfaites ", in Oeuvres Choisies, traduçào de O. de Meulenaere, vol. II, P. 1

${ }^{26}$-A respeito, consultar Danicla CARUSO, La uulpa in contrabendo, l'esperienza staturitenre e quella italiana, Giuffrè Editore, 1993. Vide também nosso comentário sobte o livro, in Revue Internationale de Droit Contparé, vol. 3-1997, p. 724 .

29 - Sabe-se ainda muito pouco a respeito dessas ações, mas é fato incontroverso a existência de très diferentes listas, onde estão elas enumeradas, uma de Cicero (in De Officiss), uma de Gaius (in Institutaj) e a terceira no Corpus Juris Civilis de Justiniano.Para um melhor aprofundamento sobre o tema, consultar Max KASER, Römisctles Privatrecht, Juristisches Kurz -Lehrbuch, $15^{2}$ edição, 1989, p. 370. Em língua francesa, o clássico M. VILLEY, te droit ronain, PUF, 1945. Na literatuta brasileira, breves teferèncias à Bona Fides no direito romano, in $A$ Boa Fé no Direito Privado, de Judith MARTINS-COSTA, ed. RT, 1999, pp. 111 a 124 e notas, sobretudo as de número 71 e 72. 


\section{C) A Codificação da boa fé no século XIX}

A Alemanha e o Japão são povos, há séculos, dedicados ao comércio. Mas as semelhanças entre as duas potências não terminam af, pois o protestantismo e a moral japonesa apresentam características que os aproximam sobremaneira, a ponto de constituírem comportamentos muito próximos. Tal é o caso dos gim, conjunto de regras norteadotas de cada tipo de relação humana, regras fundadas na tradição e no sentimento de afeição (ninjô) que une os indivíduos nas suas relações e, aquele que não as observa é egoísta, porquanto busca primordialmente o seu interesse, em vez de obedecer à parte mais nobre de sua natureza.

O primeiro jurista japonês a consagrar um estudo à noção de Boa Fé foi o professor Ishizaka, em 1915. Para ele, a função essencial da boa fé era ser um critério (kijun) capaz de possibilitar a determinação do objeto da prestação ou a maneira de seu cumprimento.

Em $1920^{30}$, uma decisão do Tribunal Supremo japonês aplicou pela primeira vez o Princípio da Boa F’é Objetiva, princípio «que domina o direito das obrigaçôes », determinando, a partir daí, uma pesquisa mais aprofundada sobre o seu conceito.

$\mathrm{Na}$ verdade, os motivos pelos quais a Boa Fé foi introduzida no Código Civil japonês, remontam à doutrina anterior à Codificação, tais a busca por uma maior adaptabilidade do direito as diversas situações da vida, e a vontade de instituir o primado do coletivo sobre o individual. A Boa Fé Objetiva no Japão é tida como uma norma, cujo fim precípuo é o de limitar a autonomia da vontade e, ao mesmo tempo, permitir ao magistrado melhor adaptar a sua decisão ao caso concreto.

A doutrina encarregou-se desse estudo e, graças as suas valiosas contribuições, o Minpô recepcionou, em seu texto, a Boa Fé, tendo em vista uma maior flexibilidade do direito, certamente sob uma forte e evidente influência da Escola do livre direito, o Freirechtsbewerging alemão ${ }^{31}$.

Contudo, ainda assim, a introdução do princípio da Boa Fé objetiva só foi possível mediante uma reforma constitucional, reforma necessária à adaptação do país as novas circunstâncias, criadas em conseqüência da $2^{a}$. guerra mundial, fator da destruição material do país do Sol nascente. As forças de ocupação, ou seja, os norte-americanos, foram os grandes incentivadores da elaboração de uma Constituição democrática para o país, o que desencadeou, de maneira natural, uma série de adaptaçōes do Minpốa nova realidade juridico-política japonesa ${ }^{32}$.

30 -Tribunal Supremo, 18 de dezembro de 1920 , Minroku, $\mathrm{n}^{\circ}$ 26, p. 1947, ref. por Béatrice JALUZOT, in L a bonne foi dans les contrats, Dalioz, 2001, p. 51, nota 1.

31 -Segundo Eugen EHRLICH, um dos mais ardorosos defensores da atribuição de um poder pretoriano aos juizes, existe, paralelamente ao direito emanado do Lstado, un direito livremente constituido, o qual deve ser levado em conta pelo magistrado, da mesma forma que a lei. O controverido pensador ensinava que o livre direito é composto pela "equidade (Billigkeit)», pelo "sentimento do justo (richtiges Recht)", da "razão prática (praktisches Vernunft)" e, sobretudo, da «sentença de acordo com os valores sociais (Werturteil ) $)$. A respeito desta doutrina, há inúmeras obras, mas talvez as mais interessantes sejam a de H. KANTOROWICZ, Der Kampf um die Rechisuissenschaft, publicada em 1906 e a reação inflamada de François GÉNY a respeito, o tão conhecido Méthode dinterprétation ef soutres en drait positif, cuja primeira edição data de 1899, sendo a segunda, mais difundida, catacla de 1919.

32 -Sobre a evolução da ocidentalizaçăo do Japão e a influència americana no país, vide Edưino REISCHAUER, op.cit. supra. 
Para levar a cabo este projeto de democratização, ao mesmo tempo em que era reformada a Constituição, votou-se uma lei sobre medidas de urgência para o direito civil. A comissão de reforma do código civil apresen tou quatro projetos, cujo objetivo era o direito civil como um todo, mas, somente aquele relativo à reforma do artigo $1^{\circ}$ do Mintó foi aprovado, tendo como fundo o princípio maior, o do bem estar do povo (artigo $1^{\circ}$, alínea 1, e a referência à Boa Fé, na alínea 2) e o da proibição do abuso de direito (artigo 1, alínea 3).

É interessante observar que o Japão introduziu a norma relativa à Boa Fé Objetiva em seu Código Civil, visando, por meio dela, a adaptação do direito civil aos novos valores democráticos, consagrados na Constituição do país, também recentemente democratizada.

A seguir, passaremos a analisar as diferentes configuirações da Boa Fé Objetiva nos Códigos objeto deste estudo.

II Parte: $O$ alcance dos três textos relativos à Boa Fé objetiva, em matéria contratual, nos Códigos Civis, alemão, brasileiro e japonês.

Os legisladores destes três países redigiram de forma mais ou menos semelhante a regra onde impõem aos contratantes o dever de atuaten, na consecução do contrato, de acordo com os diranes da boa fé objetiva. É o que se depreende dos textos a seguir transcritos:

A) As disposições normativas a respeito da Boa Fé Objetiva, nas Codificações analisadas

a) Código alemão de 1900:

$\$ 242$ : O devedor tem a obrigafäo de executar a prestação, tal como o exigem a confiança e a fidelidade lavando em considerajão os usos de tráfico. ${ }^{33}$

b) Código Civil brasileiro de 2002:

art. 422 : Os contratantes são obrigados a guardar, assim na conclusão do contrato, como em sua execufão, os principios da probidade e boa fé.

c) O Código Civil japonês, o Minpô, com a redação dada em 1947:

arrigo $1^{\circ}$ alínea 2: O exercício dos dirritos e a execufãa das obrigaçöes são coisas que devem ser feitas de boa fé e com lealdade.

Postas as três normas relativas ao princípio da boa fé objetiva nos Códigos aqui referidos, surge uma primeira indagação, a de determinar-se a verdadeira natureza das normas relativas à Boa Fé objetiva, em cada um dos sistemas de direito privado em análise: a que categoria de notma pertence a Boa Fé Objetiva? Seria uri standard jurídico ou um princípio getal?

Alguns ordenamentos a consideram como um standard, servindo de critério de julgamento, outros, como principio, o que lhe dá maior importância.

1) A boa fé objetiva como standard jurídico:

Como standard, a boa fé objetiva pode receber acepções muito variadas, distintas segundo a matéria onde é aplicada, pois o standard dá uma medida média de conduta social, suscetivel de se adaptat às particularidades de cada hipótese determinada. Desta sorte, a Boa Fé Objetiva é um conceito de geometria variável $e^{\beta A}$, cuja constância é duvidosa, mas cuja vantagem

33 - Causa certa perplexidade, o fato de o $\$ 242$ ter, como destinatário, aparentemente, somente o devedor.

${ }^{34}-A$ expressão, inúmeras vezes citada, é da autoria de Béatrice JALUZOT, in op. cit. 
é a flexibilidade. Exemplo dessa acepção, é a forma como ela está prevista no Code Civil francês e no Uniform Commercial Code americano ${ }^{35}$.

Os alemães e japoneses optaram pela concepção principial da boa fé objetiva ${ }^{36}$. Esta qualificação vem sendo adotada, a cada dia mais, por outros sistemas.

\section{2) A Boa Fé Objetiva como princípio:}

Como princípio, a Boa Fé Objetiva desempenha três funções assim entendidas : interpretação, concretização e controle.

2.1) A função interpretativa da boa fé:

De acordo com o $\$ 157$ do $B G B$, as contratos devem ser interpretados conforme exige a boa fe levandorse en conta os usos.

O legislador brasileiro de 2002, na parte geral do Código Civil, em seu artigo 113, dispôs de forma análoga à do legislador do BGB: Os negócios jurídicos devem ser interpretados conforme a boa fée os usos do lutgar de sua celebraf̧ấ, $\sigma^{37}$.

Já o Minpô não contém regra expressa referente à interpretação conforme a Boa Fé, conferindo ampla discricionariedade ao juiz na matéria.

Na verdade, a incidência da Boa Fé na teoria da interpretação japonesa é considerada exclusivamente uma obra da doutrina, preconizando-se a interpretação em função do fim perseguido pelos contratantes, depois pelos usos, pelo direito supletivo e, por último, em virtude da Boa Fé3 ${ }^{38}$.

35 -Arcigo 1134 do $C N$ as convenp̧óes legalmente formadas têm valor de tei em relafão aquteles que as cunstituíram. Elas somente podem ser revogadas por seu consentimento mútuo, ou por causas autorizadas pela lei. Elas devem ser executadas de boa fé. Já o UCC americano, em seu $\$ 1-102$, dispõe que as partes podem, mediante as cláusulas contratuais, quais os standards deverão ser observados durante a execução do contrato.

${ }_{36}$ - Principio é una idéta geral, extraida de um conjunto de regras ligadas entre si por uma curta relaçáa lógica, e é a idéáa comum, situada na base de todas essas regras, que é formulada sob a forma de uprincipion O trapo mais caracteristico do principio e a abstrapäa. Um principio é extraido das regras. Mediante um trabalho de pura induçäo logica, eliminanda-se as partixilaridades de cada regra, para manter apenas uma conatpgäs ideal e puramente subjetiva, e dela fazer uma realidade permanente e objetiva, cf. AL-SANHOURY, Le standard juridique, ref. por BJALUZOT, op.cit. p. 71. Lim portuguès, vide o excelente estudo de Humberto Bergmann ÁviLA Teoria dor prinoípios, da definiģa à aplitaçáo dos princípios juridicos, Editora Malheiros, 04-2003, 127 páginas .

37. O nosso vetusto Código Comercial de 1850 já dispunha no mesmo sentido, em seu artigo 131 : Sendo necessário interpretar as cláusulas do contrato, a interpretafäo, atem das regras sobreditas, será regulada sobre as suguintes bases: 1.0 inteligéncia simples $e$ adequada, que for mais conforme à boa fé, $e$ a o verdadeiro espirito e natureza do contrato, deverá sempre prevaleeve á rigorosa e restrita significą̧áa das palavras. Inciso 4, : o uso e prática geralmente observada no comiervio nos casos de mesma natureza, e especialmente o costume do lugar onde o contrato deva ler execufăo, prevalecerá a qualquer inteligência em contrário que se pretenda dar às palavras. ${ }^{262}$-A titulo de exemplo, vale referir a decisão da Corte Suprema Japonesa, em 1957, afirmando a boa fé näo bem sha aplicafáo limitada exclusivamente ao exervicio dos direitos, à execufáa das abrigaçoes, tha deve servir de norma de interpretafão do teor do conirato Ref. por B. JALUZOT, op,cit.p. 170, n 622 .

38-A título de exemplo, vale referir a decisão da Coxte Suptema Japonesa, em 1957, afirmando a boa


de interpretafia do teor da contrato. Ref. por B. JALUZOT, op,cit.p. 170, $\mathrm{n}^{\circ} 622$. 
Os juízes japoneses costumam interpretar livremente as normas legais, apoiando-se numa ratio ou natureza das coisas, os denominados jori, invocando em suas decisões tanto a Boa Fé como os bons costumes. O juiz nipônico é bern mais livre do que o europeu ou o brasileiro, tem ampla liberdade, não estando tão adstrito à lei como no Ocidente. Esta discricionatiedade pode ser algo bom, mas não deixa de representar uma certa insegurança para o jurisdicionado. É certo também que este aspecto depende da cultura do povo, onde recorrer ao Tribunal representou, durante séculos, um ato qualificado como vergonhoso.

Sob um outro ângulo, há uma aproximação entre o direito brasileiro e o japonês, relativamente ao exercicio do direito, ambos sujeitos à Boa Fée ${ }^{39}$.

2.2) No que tange à função concretizadora da Boa Fé, há uma sintonia entre o direito alemão e o japonês, pois através da Konkretisierung, em alemão e da gutaika em japonês, é feita a determinação mais concreta do conteúdo da Boa Fé, mediante o recurso aos usos, usos locais e a certos valores. É interessante mencionar o fato de o Minpô reconhecer, no seu art. 92, a importância desses usos $^{\text {th }}$.

O Código brasileiro de 2002, em seu artigo 113, refere a Boa-Fé e os usos do lugar de sua celebração, como critérios para a interpretação dos negócios jurídicos.

No Brasil, infelizmente, a relevância dada aos usos é ainda pequena, porque a nossa tradição é demasiado positivista.

Quanto aos valores, são aqueles de cunho ético- sociais, como a lealdade, a razão, a justiça, a solidariedade, a equidade e os princípios constitucionais.

2.3) Em relação à função de controle da Boa Fé Objetiva, os três sistemas jurídicos, alemão, brasileiro e japonês coincidem num mesmo aspecto, todos concebem a Boa Fé Objetiva como uma espécie de diretiva do comportamento das partes, quando da execução contratual, diretiva essa permissiva de um efetivo controle desse comportamento, pelo magistrado.

Apesar desse reconhecimento comum, as formas de realização do controle são diferentes nos três ordenamentos.

a- No sistema alemão, o controle do exercício da autonomia da vontade é realizado de maneira ampla pelo juiz, valendo lembrar aqui a teoria do abuso de Direito, nascida da exceptio doli generalis, ressuscitada pela jurisprudência do final do século passado. Esta construção foi vinculada ao $\$ 242$, onde se prevê a execução de boa fé das convenções. Essta construção é peculiar ao diteito alemão, se bem sejam as duas noções indissociáveis, na maioria dos sistemas jurídicos.

Foi tambén com base na Boa Fé Objetiva, que o juiz alemão controlou a edição de

39 - Mintht, artigo 1, alínea 2, transcrito supra, e o artigo 187 do Cádigo de 2003, Tanbém comete aio ilicito o ritular de un direito que, ao exercet-lo, excede manifestaneente os limites impostos pelo sen fim ecomómico ou social, pela boa fé ou pelos bons cosiumes.

"A -Artigo 92: Exxissindo um costume diverso da loi on do regulamento, mas näo relacionado a Onlem Pública é preciso levar em conta se os participantes de um ato juridico tinbam a intemsäo de observar este costume, de modo que o costume deve prevalecer:

41 - A Allgemeine Geschäfts Bedingung Gesetz de 1976. V. nosso đIneficácia das cláusulas abusivas», in Revista de Direito do Consumidor, $\mathrm{n}^{\circ} 43$, julho/setembro 2002, p. 316-324. 
cláusulas abusivas nos contratos de consuno, antes mesmo da publicação da AGBG, de $1976^{41}$. Nos contratos entre comerciantes, o controle pode set menos incisivo, não obstante, até mesmo essa categoria pode ser sujeita a controle judicial, conforme autoriza o $\$ 9$, da mencionada lei de 1976, sobre condiçôes gerais de negócios.

b- No Código Civil brasileiro de 2002, está consagrado o controle do exercício da autonomia da vontade, mediante a aplicação do artigo 422, onde o legislador impõe aos contratantes o dever de guardar, assim na conclusão do contrato, como em sua execução, os princípios de probidade e Boa Fé. A exemplo do que ocorte no sistema alemão, mencionamse, no diploma de 2002, os contratos de adesão (condiçōes gerais de negócios), determinando o legislador a nulidade das cláusulas onde se estipule a renúncia antecipada do aderente a direito resultante da natureza do negócio ${ }^{42}$. Anteriormente à publicação do novo Código Civil, a doutrina nacional já havia sido pródiga em obras relativatnente às funções da Boa Fé Objetiva ${ }^{43}$, inclusive a de controle, assim como a jurisprudência de nossos tribunais, atingindo niveis de verdadeira excelência, ao exercer a função controladora do exercício da autonomia da vontade ${ }^{44}$.

c- Quanto ao direito japonês, apesar da existência da possibilidade de arnpla intervenção do juiz, o controle da autonomia da vontade pelo magistrado tem sido exercido de maneira «circunspecta » como acertadamente refere B. Jaluzot ${ }^{45}$.

Relativamente à sanção ao exercício abusivo do Direito, com assinilação à violação ao princípio da Boa Fé, percebe-se uma influência francesa muito grande no direito japonês, nesta matéria. Para alguns autores, uma vez que a Boa Fié delimita o exercício de direito, o seu exercício em desacordo com os ditames dela, será considerado abusivo, porquanto o direito subjetivo deve ser exercido de forma normal, dentro de certos limites e rendo em vista um interesse juridicamente protegido.

O fundamento para a sanção ao exercício abusivo do diteito, seria a tesponsabilidade delitual, identificando-se o abuso de direito ao ato ilícito.

Com efeito, utn artigo publicado no Japão em 1906, faz menção ao abuso de direito, e nele se nota nítida influência do pensamento de Josserand, ${ }^{4,5}$ em sua obra publicada em 1905.

${ }^{42}$ Cf. axt. 423 do Código Civil de 2003, Quando bouver no conbrato de adesäo clausulas ambiguas ou contraditoriar, dever-se-d adotar a interpretafäa mais favoratel a aderente.

${ }^{43}$-O grande esudioso e " descobridor " de todas as potencialidades do princípio da Boa Fé Objetiva no Brasil foi Clóvis do COUTO e SILVA, com sua obra $A$ Obrigąáa como Processo, em 1976, Ed. José Bushatsky.

44 - V. referências jurisprudenciais, in J. MARTINS-COSTA, op. cit. p. 455 e segs.

45 -In op. cit., p. $238, \mathrm{t}^{\circ} 888$.

${ }^{45}$ De l'esprit des droits et de leur relativité, thérie dite de l'abus des droitsy).

${ }^{47}$ - La bonthe foi dans la formation du contrat, xappott japonais, in La bonne foi, joumnées touisianaises, Travaux de l'Association Herri Capitant, 1992, p. 143. 


\section{B) As variações da concepção principial da Boa Fé Objetiva}

A concepção da Boa Fé objetiva como um princípio não está imune a algumas diferenças nos três ordenamentos em análise, a Alemanha, o Brasil e o Japão.

Em $1^{\circ}$ lugar, a posição onde está o princípio, no caso do Japão, logo no início do Minpô. Seu âmbito de ação se circunscreve ao direito civil, excluindo o direito público, mas conferindo-lhe uma posição de destaque, conforme atestam as palavras dos mestres K. Kitamura, H. Morita e A. Omura, para quem a boa fé, no Minpâ, foi «erigida à condição de primeiro violino, encarregada de conduzir toda a orquestra das regras de dixeito civil $\rangle^{47}$.

O Direito alemão, por sua vez, concebe a Boa Fé Objetiva como uma norma supetior, dominando todo o sistema, cnquanto o japonês, como se observou, não the atribui tamanha força, e é mais reservado quanto ao âmbito de sua aplicação.

No Brasil, pode-se dizer que a Boa Fé Objetiva é entendida, algumas vezes, como standard $^{t 8}$, em outras, como princípio. Ela está subentendida no Código Civil de 1916, onde é pressuposta, existindo como um princípio subjacente. No Código de 2002, está prevista expressamente, nos artigos 113 e 422 , tendo aplicação em outras disciplinas além do Direito Civil, por exemplo, no direito do trabalho, no processo civil, e no direito administrativo.

Veremos a seguir, como a jurisprudência, nos três sistemas aludidos, desenvolveu uma série de deveres, com fulcro na Boa Fé Objetiva, com o fito de complementar o conteúdo do contrato avençado entre as partes.

C) A Boa Fé Objetiva, instrumento de criação pretoriana: os deveres anexos e acessórios incidentes na relação contratual, um segundo estágio da concretização efetuada pelo juiz alemão, brasileiro e japonês

Os três sistemas aqui referenciados reconhecen a existência de deveres nascidos da incidência do princípio da boa fé objetiva no contrato. Contudo, a sua criação deve ser tributada exclusivamente à jurisprudência, sendo seu papel o de influenciar sobremaneira o direito dos contratos e da responsabilidade civil.

1) O direito alemão funda todas as obrigações acessórias no princípio da Boa Fé Objetiva, seja no $\$ 157^{49}$ seja no $₫ 242$ do $B G B$. Esta idéia de permitir ao intérprete complementar o conteúdo da relação contratual, mediante a inserção de deveres acessórios, remonta à época dos trabalhos preparatórios da elaboração do BGB. A jurisprudência alemã criou, ao longo dos anos, certas obrigações, muito precisas, constituindo verdadeiras regras de direito material. De acordo com a dourrina germânica, existem três grande categorias

48 - Consultat a respeito dessa concepção, Judith MARTINS-COSTA e Gerson BRANCO "A Boa Fé como Modelo (Uma aplicação da Teoria dos Modelos de Miguel Reale) ", in Diretrizes Teóricas do Novo Cótigo Cinil brasileiru, Editora Sataiva, 2002, pp. 187 a 226.

4) -Os contratos devem ser interpretados como o exige a boa fé, levardo em considerasâa os usos. 
desses deveres, o de cooperação $0^{50}$, o de informaçãa $0^{53}$ e o de proteção $0^{52}$, os quais deram surgimento a várias outros, como o de fidelidade (Treupflicbt), cuja aplicação se restringe a apenas dois tipos de contrato, o de trabalho e o de sociedade.

2) Já o Minpô tem dois fundamentos para os deveres acessótios, os fuzi yimu, o art. $1^{\circ}$, alínea 2 e o artigo 415 , onde se lê, a execufäo deve ser feita segundo o real conteúdo da obrigação. De acordo com a maioria da doutrina nipônica, é difícil conciliar os dois fundamentos.

O direito japonês teconhece como deveres acessórios o de informat, de proteger ${ }^{53}$, de atuar com diligência e o de cooperar ${ }^{54}$.

3) No direito brasileiro, a concepção cooperativa do contrato nele percebe um feixe de vínculos, uma espécie de estrutura (Gefûge) onde cada parte pode ser destacada da outra, sem prejuizo para o todo, desta sorte, paralelamente à obrigação principal, surgem os deveres acessórios, anexos e secundários, alguns até mesmo independentes da obrigação principal, servindo o seu cumprimento, para um melhor adimplemento da principa $1^{55}$. De acordo com o pensamento de Clóvis do Couto e Silva ${ }^{56}$, todos os deveres anexos podem ser considerados como

50 -Reconhecida pela RG, a Corte Suprema alemã, já em 1920. V..RGZ, 101, p. 47. Esta obrigação consistiria en que o devedor e o credor estāo obrigados a proporcionar as candiğös para o desenvolvintento do contrato afastar os eniraves à sua execuğo, mediante uma estreita cooperafäo, cf. o Comentário Palandt/H. Heinetius, $₫ 242, \mathrm{n}^{\circ}$ 32. O tema é pouco versado na doutrina francesa, contudo, para uma visão comparatista do tratamento da cooperação contratual naquele país, ver o interessante estudo de François DIESSE, "le devoir de coopération comme príncipe directeur du contrat ", in $A p h D, 43,1999$, p. 259 a 302.

51 - O Direito alemão nào reconhece uma obrigação geral de informação, mas criou inúmeras outras, dela derivadas. Papel sobremaneira importante é reconhecido à obrigação de informar na fase précontratual. Vide nosso estudo, "Dano pré-contratual: uma análise comparativa a partir de três sistemas jurídicos, o continental eutopeu, o latino-americano e o americano do norte ", in Revista de Informạăo Legislativa, $\mathrm{n}^{\circ} 136$, out./dez. 1997, p. 169 e segs. Para o dever de informar em geral, no direito privado, consultar Christoph FABIAN, Dever de Informar no Direito Civil, Editora RT, 2002, 176 páginas .

${ }^{52}$ - Espécie muito heterogènea, pois reúne vários tipos de obrigações secundárias, referenciadas à Boa Fé, como as de segurança, prudência e garantia .

53 -V. decisão da Corte Suprema japonesa, datada de 17 de outubro de 1991, onde fol mencionada a existência de um dever de proteção, pot parte do proprietário negligente, quanto às condições de um prédio, onde ocorrera um incêndio, condenando-o ao pagamento de perdas e danos pela inexecução do contrato, com fundamento no princípio da Boa Fé Objetiva. Ref. por B.JALUZOT, op.cit.p. 520.

${ }^{54}$ - Va decisão da Corte Suprema japonesa, em 30 de maio de 1968, onde foi dito que a parte havia fallado com sua obrigajăo de contribuir para a realizasa do fint almejado no contrato. V. B. JALUZOT, op.cit. 515, nota 03.

55 -O Direito das Obrigaçōes brasileiro tem nítida inspiração romana, daí a sua proximidade con o direito alemão.Va respeito, ESSER/ SCHMIDT, Sibuldrecht, Band I und II, Allgemeiner Teil, FMüller Juriscischer Verlag GmbH, Heidelberg, $7^{2}$.ed., 1992, e, para o direito brasileiro, Francisco PONTES DE MIRADO, Tratado de Direito Privado, Rio de Janeito, Borsoi Editor, 1972 além de Clóvis do COUTO e SILVA, A Obrigafáa como Processo, já referida. Apesar da enorme relevância desse ramo do Direito Privado, nosso novo Código, diversamente do Code Napoléon e do $B G B$, não evoluiu na natéria, não recepcionou as transformações derivadas da evolução das relações negociais, não absorveu modelos estrangeiros mais avançados. Para o Direito brasileiro, consultar Judith MARTINS-COSTA, Comentários ao Novo Código Civil , direito das obrigacóes,volume V, tomo I, arts. 304 a 388 , Editora Forense, 2003. Para o Direito francês, Camille JAUFFRET-SPINOSI, " La réforme du droit des obligrations ", D. 1989, p. 657. Em relação ao direito alemão, em língua francesa, Filippo RAINIERI “ La nouvelle partie grénérale du droit des obligations ", in Reque Intemationale de Droit Compare, $\mathrm{n}$ " 4, 2002, p. 941. Eim alernão, P. HUBER / FAUST, Scbuldrecbtsmodernisierung, Einfübrung in das newe Recht, C.H.Beck, München, 2002.

56 -Op. cit. p. 117. 
deveres de cooperaçã $0^{57}$, ressaltando, porém, a existência de autores que dão significado restrito a esses deveres, abrangendo apenas os de auxilio, no sentido de o fim (adimplemento) da avença só poder ser atingido mediante a mútua cooperação das partes.

O mesmo autor menciona, como parte da categoria de deveres anexos, os de indicação e esclarecimento, cujo cumprimento se dá em favor do outro contratante ${ }^{58}$.

Uma observação interessante diz tespeito à terminologia empregada nos três sistemas em relação às consequiências da incidência do princípio da Boa Fé Objetiva na relação contratual : enquanto os franceses, aqui pouco mencionados, utilizam a expressão «obrigações acessórias », os alemães, brasileiros e japoneses preferem qualifica-las como « deveres». A razão dessa diferença de tratamento talvez derive da consideração dos « deveres acessórios » como algo extetno às partes, não originado da vontade dos contrarantes, os quais convencionam, pelo exercício da autonomia da vontade, apenas a obrigação principal. Ora, a incidência do princípio da Boa Fé Objetiva na relação contratual, impõe-thes deveres (e não obrigações), porquanto inafastáveis por sua vontade, sujeitando ambas as partes.

\section{Conclusão:}

Após essas brevíssimas reflexões de cunho comparatista, chegamos ao momento da realizarmos a síntese das idéias aqui expostas :

a) A recepção do modelo jurídico romano deu-se de forma distinta em cada um dos três ordenamentos aqui analisados;

b) devido a fatores de cunho histórico, filosófico, religioso e ideológico, a adoção do princípio da Boa Fé Objetiva redundou em algumas diferenças na sua acepção nos três sistemas jurídicos objeto da análise aqui efetuada;

c) em que pesem tais diferenças, pudemos, contudo, observar set a adoção do Princípio da Boa Fé Objetiva um elemento de aproximação entre as três concepções de contrato analisadas, aproximando-as até mesmo daqueles modelos criados pelas organizações internacionais, por exemplo, o da Convenção de Viena de 1980 sobte Venda Internacional de Mercadorias, do Code Unidroit sobre Contratos Internacionais de Comércio ${ }^{59} \mathrm{e}$ do Code Européen des Contratts $5^{50}$;

${ }^{57}$ Consultar, deste autor, também Les principes fondamentaux de la responsabilité cinile en droit brésilien et comparé, Cours fait à Paris, Université de Paris XII, 1988, dat, onde o autor demonstra compartilhar da concepção alemã de telação obrigacional, pois assim se inanifesta: ....Aujourd'bui, par lapplication du principe de la bonne foi an droit des abligations, le rapport obligatoire est consideré aussi comme un ordre de coopération entre les parties pour accomplir lintérêt du créditeats. P. 01.

${ }^{58}$. Vide Mário Júlio de ALMEIDA COSTA, Direito das obrigąöer, Editora Almedina, 1994, 6a.edição, sobretudo páginas 88 a 98 .

59 Publicados pelo UNIDROIT(Institut International pour l'Unificacion du Droit privé Privado), Roma, 1994, 262 páginas, em várias versões: alemão, árabe, chinês, espanhol, holandês, húngaro, italiano e russo, sendo a versão oxiginal ern inglês.

6i) -Avant-Projet, élaboré par l'Académie des Privatistes Européens, Coordinateur Giuseppe GANDOLFI, livre premier, Giuffrè Editore, 2002. 
d) no que se refere ao direito japonês, testa aberta a indagação formulada inicialmente: pode-se falar em uma real e efetiva ocidentalização do direito civil japonês? Nossa resposta talvez possa ser interpretada como uma ousadia, pois entendemos que, para alguns efeitos, ela existe, mas para outros, não.

Com efeito, a tradição e a cultura japonesas são mais fortes do que toda e qualquer inspiração externa. E ousamos ir mais longe: melhor seja assim, pois o povo japonês deve conservar a sua identidade, seus valores culturais. Como visto, a manutenção e conservação intactas de suas tradições, o amor pela sua cultura milenar, seu sentimentalismo místico, sua mentalidade voltada mais para a poesia do que para a lógica, esta um dos substratos dos Códigos europeus, o afastam do mundo ocidental.

Pessoalmente acreditamos consistir este aspecto o maior encanto da civilização japonesa: um país extremamente desenvolvido em todos os campos do conhecimento, detentor de uma tecnologia de ponta em vários setores, cujo povo respeita o próximo independentemente de qualquer regra juridica impositiva, movido por um costume milenat, fator de união e entendimento na sociedade japonesa. Para nós, essa maneira de conceber as relações sociais deve ser um excelente exemplo a ser initado. 